\title{
Mutants with Increased Sensitivity to Canavanine in the Fungus Coniochaeta velutina
}

\author{
By H. TAN* AND F. COOKE \\ Biology Department, Queen's University, Kingston, Ontario, Canada
}

(Received 5 February 1978; revised 3 May 1978)

Mutants of Coniochaeta velutina with increased sensitivity to canavanine were derived from wild-type, pyr-3 (presumably defective in carbamoyl-phosphate synthase for pyrimidine synthesis), arg (blocked in steps prior to arginine formation) and pro (blocked in steps prior to glutamate semialdehyde formation) strains, and were classified into eight distinct groups by genetic mapping. Four canavanine-sensitive genes ( $c n s$ ) were allelic or very tightly linked to known $\arg$ loci. The pairs of genes involved were $c n s A$ and $\arg -3$ (arginine requirer), $c n s B$ and $\arg -7$ (citrulline requirer), $c n s C$ and $\arg -2$ (citrulline requirer) and $c n s G$ and $\arg -1$ (ornithine requirer). Another ( $c n s F$ ) was mapped in linkage group III.

A relationship was shown between the level of intracellular arginine and the extent of canavanine sensitivity; cns strains contain less intracellular arginine than the less sensitive wild-type. In most cases, this was shown to result from mutations affecting the enzyme(s) involved in arginine metabolism. cns $A$ and $c n s G$ were thought to be affected in arginine- and ornithine-synthesizing enzymes, respectively. $c n s B$ and $c n s C$ exhibited a requirement for citrulline when the two genes were combined and were suggested to be loci specifying the two polypeptide chains of carbamoyl-phosphate synthase for arginine synthesis. $c n s H$ was the locus controlling ornithine carbamoyltransferase. The metabolic lesions of the other cns mutants ( $c n s D$, cnsE and $c n s F$ ) were unclear.

Of the eight cns mutants, six could suppress $p y r-3 M$ and/or pro mutations: $c n s G$ was able to suppress pyr-3M; cnsB, cnsE, cns $D$ and $c n s F$ were effective in suppressing pro; cns $H$ suppressed both pyr and pro. The mechanism of the pyr and pro suppressions was explained on the basis of metabolic cross-feeding.

\section{INTRODUCTION}

The study of mutants in micro-organisms resistant or sensitive to amino acid analogues has led to a greater understanding of the control mechanism of metabolic pathways and the nature of analogue sensitivity (Moyed, 1964; Richmond, 1965). A well investigated system is the regulation of arginine biosynthesis in Escherichia coli (Maas, 1961) and Saccharomyces cerevisiae (Bechet et al., 1970) elucidated by studies with canavanine-resistant mutants. In general, an overproduction of arginine due to loss of a control mechanism and an impairment of arginine uptake have been shown to account for their resistance to canavanine. The other mode of resistance found in micro-organisms such as Pseudomonas (Kalyankar et al., 1958 ) and Streptococus (Kihara \& Snell, 1957) was attributed to a canavanine-detoxifying system which degrades canavanine to a non-toxic product.

In filamentous fungi, knowledge of canavanine resistance or sensitivity and its relation to the regulatory mechanism of the arginine pathway is limited to Neurospora crassa and Aspergillus nidulans. In Neurospora, resistance to canavanine was shown to be by a gene

* Present address: Plant Sciences Division, Rubber Research Institute of Malaysia, P.O. Box 150, Kuala Lumpur, Malaysia. 
coding for the production of a canavanine-cleaving enzyme and at least three other genes modifying the uptake system for canavanine or arginine (Bauerle, 1963; Bauerle \& Garner, 1964; Logan, 1969). In Aspergillus, certain proline suppressor mutants which were sensitive to canavanine were shown to be affected in enzymes related to arginine metabolism (Weglenski, 1967).

This study extends a similar type of investigation using the ascomycete fungus Coniochaeta velutina. Previously we have reported chs (canavanine-sensitive) strains that were revertants of an arginine mutant (Tan \& Cooke, 1969). The cns mutant behaved like a wildtype but was sensitive to canavanine. We suggested that canavanine sensitivity may be governed by the level of endogenous arginine. Wild-type Coniochaeta appears to produce sufficient arginine to counteract the inhibitory effect of canavanine whereas the cns strains have reduced arginine production due to the mutation.

This paper describes the genetical location and growth characteristics of a large sample of cns mutants produced by various methods, their roles on the pyrimidine, arginine and proline pathways and the nature of canavanine sensitivity.

\section{METHODS}

Strains. The strains of Coniochaeta velutina used were the wild-type, strains auxotrophic for pyrimidine (pyr), arginine (arg) or proline (pro) and canavanine-sensitive (cns) strains. The induction and nutritional requirements of the auxotrophic mutants have been described earlier (Tan, 1968; Cooke et al., 1969; Paterson, 1969; Paterson et al., 1969). Canavanine-sensitive mutants were obtained from the wild-type strains following $N$-methyl- $N^{\prime}$-nitro- $N$-nitrosoguanidine treatment (Paterson, 1969; Paterson et al., 1969). In addition, cns strains were produced from pyr-3, arg-2, 3,7 and pro-1,2 mutants by u.v. irradiation (Tan, 1971). The treated conidia from these strains were plated on 25 to $30 \mathrm{ml}$ of solid glucose minimal medium, GMA (Cooke et al., 1969). After 5 to $6 \mathrm{~d}$ incubation at $25^{\circ} \mathrm{C}$, the fungal colonies were replica-plated on to GMA containing $1 \mu \mathrm{g}$ canavanine $\mathrm{mI}^{-1}$. Colonies which grew very poorly or not at all on canavanine medium after 5 to $6 \mathrm{~d}$ incubation were classified as cns mutants.

Media. GMA, with or without appropriate supplement (L-arginine, citrulline, ornithine, proline, lysine and uracil from Fisher Scientific Co. and L-canavanine from Sigma), was used for growth experiments and characterization of recombinants. The concentrations of these supplements were $1 \mu \mathrm{g} \mathrm{ml}^{-1}$ unless stated otherwise. Liquid Vogel minimal medium, VM (Vogel, 1956), was used to culture mycelium for enzyme assays and amino acid determinations. The crossing medium was $1.2 \%(\mathrm{w} / \mathrm{v})$ Difco malt extract (Cooke et al., 1969).

Genetic analysis. This was done as described by Cooke et al. (1969). To detect linkage between cns mutations, or between $c n s$ and auxotrophic mutations, a rapid screening technique similar to that described by Markert (1952) was employed. If a prototroph frequency from a cross was significantly lower than $20 \%$, linkage was suspected and a random ascospore analysis using the individual isolation method or the replicaplating method was done. As complementation tests in heterokaryons were not possible, a prototroph frequency lower than $0 \cdot 1 \%$ was considered a close approximation of allelism (or very tight linkage).

Growth conditions. Growth experiments were done on $25 \mathrm{ml}$ of appropriately supplemented GMA in Petri dishes. Approximately equal conidial inocula were transferred to a point on the test plates and incubated at $25^{\circ} \mathrm{C}$. Diameters of colonies were measured 5 to $7 \mathrm{~d}$ after inoculation.

For enzyme assays and amino acid determination, mycelium was grown in a $2.8 \mathrm{I}$ flat-bottomed Erlenmeyer flask containing 11 VM. Flasks were inoculated with a heavy conidial suspension in sterile distilled water and were incubated at $25^{\circ} \mathrm{C}$ for 3 to $4 \mathrm{~d}$ on a rotary shaker (model G10, New Brunswick Scientific Co.) operating at 70 rev. $\mathrm{min}^{-1}$.

Preparation of cell-free extracts. The mycelium was blotted dry and mixed with 5 vol. buffer ( $0 \cdot 2 \mathrm{M}$-Tris/ $\mathrm{HCl}$ buffer, $\mathrm{pH} 8$, for ornithine carbamoyltransferase and arginase; $0.2 \mathrm{M}$-phosphate buffer, $\mathrm{pH} 8$, for ornithine aminotransferase) containing $0.143 \mathrm{~mm}$-mercaptoethanol. The mixture was sonicated for $5 \mathrm{~min}$ (at $80 \mathrm{~W}$, tone 0, using a Fisher Ultrasonic Generator; Fisher Scientific Co., Ottawa, Canada) and centrifuged at $1750 \mathrm{~g}$ for $20 \mathrm{~min}$ at $4^{\circ} \mathrm{C}$. The supernatant was used immediately for enzyme assays.

Enzyme assays. The assays for ornithine carbamoyltransferase [OCT; carbamoyl-phosphate:L-ornithine carbamoyltransferase; EC 2.1.3.3], arginase [L-arginine amidinohydrolase; EC 3.5.3.1] and ornithine aminotransferase [OAT; L-ornithine: 2-oxo-acid aminotransferase; EC 2.6.1.13] were similar to those used by Weglenski (1967). For OCT assay, the incubation mixture contained $10 \mu \mathrm{mol} \mathrm{L}$-ornithine, $100 \mu \mathrm{mol}$ carbamoyl phosphate, $100 \mu \mathrm{mol}$ Tris/ $\mathrm{HCl}$ buffer (pH 8.5) and $0.15 \mathrm{ml}$ enzyme extract, in a total volume of 
$0.55 \mathrm{ml}$. For arginase assay, the reaction mixture contained $10 \mu \mathrm{mol}$ L-arginine. $\mathrm{HCl}(\mathrm{pH} \mathrm{9.5)}, 1 \mu \mathrm{mol}$ $\mathrm{MnCl}_{2}, 20 \mu \mathrm{mol}$ Tris $/ \mathrm{HCl}$ buffer ( $\mathrm{pH} \mathrm{9)}$ and $0.3 \mathrm{ml}$ enzyme extract, in a total volume of $0.75 \mathrm{ml}$. For OAT assay, the reaction mixture contained $10 \mu \mathrm{mol}$ ornithine. $\mathrm{HCl}, 10 \mu \mathrm{mol} 2$-oxoglutarate (pH 7), $20 \mu \mathrm{mol}$ potassium phosphate buffer ( $\mathrm{pH} 8.5$ ) and $0.4 \mathrm{ml}$ enzyme extract, in a total volume of $0.6 \mathrm{ml}$. The incubation periods for the OCT, arginase and OAT assays were 15 to 20,90 and 40 to $60 \mathrm{~min}$, respectively, at $30^{\circ} \mathrm{C}$. Reactions were stopped by adding $0.25 \mathrm{ml} 10 \%(\mathrm{w} / \mathrm{v})$ trichloroacetic acid (TCA) for OCT and arginase assays and $0.3 \mathrm{ml}$ TCA for OAT assays. The protein precipitate was removed by centrifugation and the supernatants from the OCT, arginase and OAT mixtures, respectively, were tested for citrulline, urea and glutamate semialdehyde (acetaldehyde was used as a standard instead of glutamate semialdehyde) (Knivett, 1954; Albrecht et al., 1962).

Protein was measured by the method of Lowry et al. (1951) with crystalline bovine serum albumin as a standard.

Determination of free arginine in mycelium. One part of acetone-dried mycelium was mixed with six parts of distilled water and autoclaved at $121{ }^{\circ} \mathrm{C}$ for $1 \mathrm{~h}$. After centrifuging at $7400 \mathrm{~g}$ for $30 \mathrm{~min}$ to remove the cell debris, samples $(0.1$ to $0.4 \mathrm{ml})$ of the supernatant were used for arginine determination by the Sakaguchi reaction (Van Pilsum et al., 1957).

Estimation of arginine excreted into culture medium. A bioassay method, basically similar to that for Neurospora, was used to test for trace amounts of arginine excreted by the fungus into culture media (Doermamn, 1945). The test medium was filtered through a Millipore filter $(0.45 \mu \mathrm{m}$ pore size) which excluded conidia from the filtrates. The filtrates were incorporated into solid VM and assayed for arginine using an arg-3 strain. GMA plates containing known concentrations of arginine were used as controls.

\section{RESULTS}

\section{Genetic analysis of cns mutants}

Eight genetically distinct groups of $c n s$ mutants, designated as $c n s A$, cns $B$, cns C, cns D, $c n s E, c n s F, c n s G$ and $c n s H$, were identified by means of numerous pairwise crosses (Table 1). From more than 100 crosses made, there were $18 \mathrm{cns} B$ isolates, $15 \mathrm{cns} C, 14 \mathrm{cns}, 4 \mathrm{cns} H$ and 2 cns $A$; cns $D$, cns $E$ and $c n s F$ had only one isolate each.

The finding of arg revertants which were canavanine-sensitive prompted an investigation into the relationships between $c n s$ and $\mathrm{arg}$. The eight distinct $c n s$ mutants were crossed with the nine known arg mutants. The pairs $c n s B / \arg -7$, cnsC/arg-2 and cnsG/arg-1 were shown to be allelic or very tightly linked since an extremely low prototroph frequency $(<0.1 \%$ among about 2000 offspring tested) was observed in each combination. The cross between cnsA and $\arg -3$ was infertile, but cnsA may be allelic to $\arg -3$ since it was produced by u.v. irradiation of an $\arg -3$ strain. $c n s D, c n s E, c n s F$ and $c n s H$ were neither allelic nor linked to the nine known arg mutants.

Mutants carrying $c n s C$ and $c n s F$ were mapped on two of the three known linkage groups. The other cns mutants did not show linkage with the markers of any known groups.

Like arg-2, cns C is linked to his- 1 in linkage group II. From nine crosses involving his- 1 and different $c n s C$ alleles, a total of 1980 canavanine-sensitive, 1991 histidine-requiring, 208 wild-type and 145 canavanine- and histidine-requiring offspring was obtained $(8 \%$ recombination). This is similar to the recombination frequency of arg-2 with his-1 (Cooke et al., 1969).

The $c n s F$ mutation was mapped in linkage group III which contains $p y r-3, p y r-2$ and pyr-1 loci (6.2 to $13.4 \%$ recombination between pyr-2 and pyr-3; $21.3 \pm 0.5 \%$ recombination between $p y r-3$ and $p y r-1 ; 23.4 \pm 0.9 \%$ recombination between $p y r-2$ and $p y r-1)$. When $c n s F$ was crossed to three different alleles of pyr-3, recombination frequencies between $23.0 \pm 4 \cdot 1 \%$ and $29.0 \pm 3.7 \%$ were obtained from a total of 755 offspring tested. When $c n s F$ was crossed to $p y r-1$ in the same linkage group, 189 recombinants were found among 391 offspring tested (48\% recombination), suggesting that $p y r-3$ is closer to $c n s F$ than to $p y r-1$. No data on recombination between $c n s F$ and $p y r-2$ are available. On the basis of these two-point results, the order could be either cnsF pyr-2 pyr-3 pyr-1 or cnsF pyr-3 pyr-2 pyr-1. 
Table 1. Strains used for genetic analyses and subsequent investigations

\begin{tabular}{|c|c|c|c|}
\hline Strain & Isolation no. & Origin & $\begin{array}{c}\text { Mutagen } \\
\text { used } \dagger\end{array}$ \\
\hline Wild-type & $\mathrm{o}_{1} \mathrm{Z}, \mathrm{o}_{4} \mathrm{Z}, \mathrm{H} 1^{*}$ & - & - \\
\hline cnsA & 1 & $\arg -3(z 64)$ & u.v. \\
\hline$c n s B$ & $\begin{array}{c}1 \\
2 \\
3 \\
\text { Others }\end{array}$ & $\begin{array}{l}\text { Wild-type }\left(\mathrm{O}_{1} \mathrm{z}\right) \\
\text { Wild-type }\left(\mathrm{O}_{1} \mathrm{z}\right) \\
\text { arg-7 (M29) } \\
\arg -7(\mathrm{M} 102)\end{array}$ & $\begin{array}{l}\text { NG } \\
\text { NG } \\
\text { u.v. } \\
\text { u.v. }\end{array}$ \\
\hline cnsC & $\begin{array}{c}1 \\
2 \\
3 \\
\text { Others }\end{array}$ & $\begin{array}{l}\text { Wild-type }\left(\mathrm{O}_{4} \mathrm{z}\right) \\
\text { Wild-type }\left(\mathrm{O}_{4} \mathrm{z}\right) \\
\text { arg-2 (M122) } \\
\text { arg-2 (z135) }\end{array}$ & $\begin{array}{l}\text { NG } \\
\text { NG } \\
\text { u.v. } \\
\text { u.v. }\end{array}$ \\
\hline cnsD & 1 & pro-1 (м317) & u.v. \\
\hline$c n s E$ & 1 & pro-2 (м324) & u.v. \\
\hline cnsF & 1 & Wild-type $\left(o_{1} z\right)$ & NG \\
\hline$c n s G$ & $\begin{array}{c}1 \\
2 \\
\text { Others }\end{array}$ & $\begin{array}{l}\text { Wild-type }\left(\mathrm{O}_{4} \mathrm{z}\right) \\
\text { pyr-3 (м608) } \\
\text { pyr-3 (м608) }\end{array}$ & $\begin{array}{l}\text { NG } \\
\text { u.v. } \\
\text { u.v. }\end{array}$ \\
\hline$c n s H$ & $\begin{array}{c}1 \\
\text { Others }\end{array}$ & $\begin{array}{l}\text { pyr-3 (м608) } \\
\text { pyr-3 (м608) }\end{array}$ & $\begin{array}{l}\text { u.v. } \\
\text { u.v. }\end{array}$ \\
\hline
\end{tabular}

${ }^{*} \mathrm{H} 1$ is a conidial isolate slightly more sensitive to canavanine inhibition than the original wild-type culture, $\mathrm{o}_{1} z$.

$\dagger$ NG, $N$-methyl- $N^{\prime}$-nitro- $N$-nitrosoguanidine; u.v., ultraviolet light.

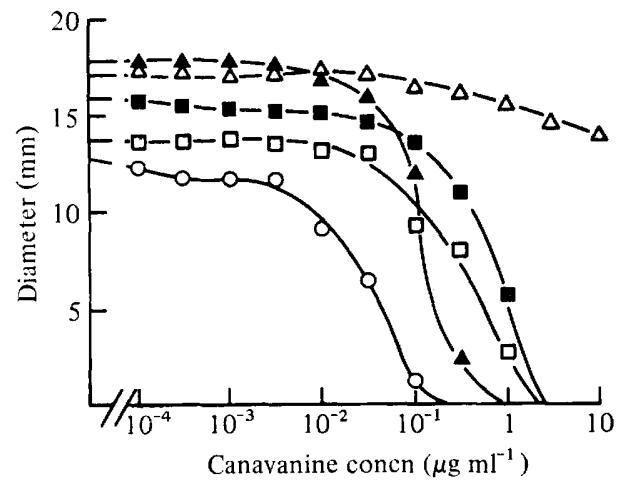

Fig. 1

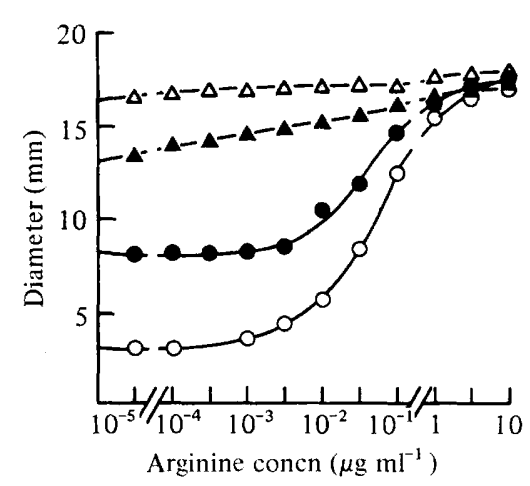

Fig. 2

Fig. 1. Effect of different concentrations of canavanine on the growth of the wild-type strain $\mathrm{o}_{1} \mathrm{z}$ $(\triangle)$ and $c n s B 1(\square)$, cnsB2 (O), cnsC1 ( $\square)$ and $c n s F 1(\Delta)$ mutants. Growth was expressed as the mean diameter of eight colonies measured $5 \mathrm{~d}$ after inoculation.

Fig. 2. Reversal of canavanine $\left(1 \mu \mathrm{g} \mathrm{ml}^{-1}\right)$ inhibition by different amounts of arginine for the wild-

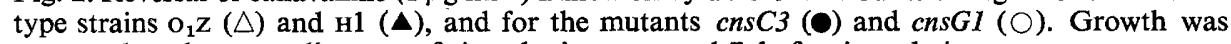
expressed as the mean diameter of six colonies measured $7 \mathrm{~d}$ after inoculation.

Quantitative inhibition by canavanine and its reversal

The responses of certain cns and wild-type strains to different concentrations of canavanine are shown in Fig. 1. There was no inhibition at a concentration below $5 \times 10^{-3} \mu \mathrm{g}$ $\mathrm{ml}^{-1}$, but $\mathrm{cns}$ strains were strongly inhibited by canavanine at concentrations greater than $5 \times 10^{-1} \mu \mathrm{g} \mathrm{ml}^{-1}$. In the presence of $1 \mu \mathrm{g}$ canavanine $\mathrm{ml}^{-1}$, the wild-type strains were inhibited by $8.2 \%$, while $c n s B 1$, cnsB2, cnsCl and $c n s F 1$ mutants showed $45 \cdot 2,100,73 \cdot 3$ and $100 \%$ inhibition, respectively. Other $\mathrm{cns}$ mutants carrying different alleles of the same gene may also be inhibited to different degrees. At $10 \mu \mathrm{g} \mathrm{ml}^{-1}$ the wild-type strains were inhibited 
Table 2. Effects of amino acids and analogues on the growth of wild-type $\mathrm{O}_{4} \mathrm{z}$ and cnsB1, cnsC3 and cnsG1 mutants

\begin{tabular}{|c|c|c|c|c|c|}
\hline \multirow{2}{*}{\multicolumn{2}{|c|}{$\begin{array}{l}\text { Addition(s) to minimal } \\
\text { medium* }\end{array}$}} & \multicolumn{4}{|c|}{ Inhibition of growth $(\%) \dagger$} \\
\hline & & Wild-type & $c n s B$ & cnsC & cnsG \\
\hline $\begin{array}{l}\text { Canavanine } \\
\text { Ornithine } \\
\text { Citrulline } \\
\text { Arginine } \\
\text { Lysine } \\
\text { Canavanine + ornithine }\end{array}$ & & $\begin{array}{l}5 \cdot 9 \\
0 \\
0 \\
-2 \cdot 9 \\
0 \\
5 \cdot 9\end{array}$ & $\begin{array}{c}59 \cdot 4 \\
0 \\
-6 \cdot 3 \\
-9 \cdot 1 \\
0 \cdot 6 \\
54 \cdot 8\end{array}$ & $\begin{array}{c}50 \cdot 0 \\
0 \\
-4 \cdot 7 \\
-6 \cdot 3 \\
1 \cdot 6 \\
50 \cdot 8\end{array}$ & $\begin{array}{r}80 \cdot 7 \\
-25 \cdot 8 \\
-21 \cdot 0 \\
-29 \cdot 0 \\
1.9 \\
35 \cdot 5\end{array}$ \\
\hline Canavanine + citrulline & & $2 \cdot 9$ & $18 \cdot 2$ & $25 \cdot 0$ & $32 \cdot 3$ \\
\hline Canavanine + arginine & $\begin{array}{l}(2) \\
(3)\end{array}$ & $\begin{array}{l}-2.9 \\
-2.9 \\
-2.9\end{array}$ & $\begin{array}{l}3 \cdot 0 \\
0 \\
0\end{array}$ & $\begin{array}{c}0 \\
-9 \cdot 4 \\
-9 \cdot 4\end{array}$ & $\begin{array}{r}0.6 \\
-6.5 \\
-16.1\end{array}$ \\
\hline Canavanine + lysine & $\begin{array}{l}\text { (2) } \\
\text { (3) }\end{array}$ & $\begin{array}{l}5.9 \\
5 \cdot 9 \\
2 \cdot 9\end{array}$ & $\begin{array}{l}50 \cdot 7 \\
32 \cdot 4 \\
18 \cdot 2\end{array}$ & $\begin{array}{l}34 \cdot 4 \\
25 \cdot 8 \\
22 \cdot 6\end{array}$ & $\begin{array}{l}54 \cdot 8 \\
25 \cdot 8 \\
22 \cdot 6\end{array}$ \\
\hline
\end{tabular}

* All supplements were added at $1 \mu \mathrm{g} \mathrm{ml}^{-1}$, except (2) and (3) contained arginine or lysine at 2 and $3 \mu \mathrm{g} \mathrm{ml}^{-1}$, respectively.

$\dagger$ Growth inhibition was estimated after $5 \mathrm{~d}$ incubation as $[100 \times$ (Difference between colony diameters on minimal and test media)/(Colony diameter in minimal medium)]. Negative values indicate stimulation of growth.

by about $13 \%$, while all the cns mutants tested were completely inhibited. It appears that $1 \mu \mathrm{g}$ canavanine $\mathrm{ml}^{-1}$ is the minimum concentration for distinguishing cns mutants from the wild type.

The inhibitory effects of canavanine could be reversed by a number of amino acids (Table 2). Arginine was the most effective in reversing inhibition, followed by citrulline, lysine and ornithine in decreasing order, except that ornithine was more effective than lysine in counteracting canavanine inhibition of the cnsGl mutant. Both arginine and citrulline stimulated the growth of all strains tested, ornithine stimulated cnsGl and lysine inhibited cns strains slightly.

Figure 2 shows the amounts of arginine required to reverse the effect of canavanine on certain $c n s$ and wild-type strains. Arginine began to counteract canavanine inhibition at $1 \times 10^{-5} \mu \mathrm{g} \mathrm{ml}^{-1}$ for one of the wild-type strains and at $10^{-3} \mu \mathrm{g} \mathrm{ml}^{-1}$ for cnsC and cnsG mutants. The reversal of inhibition of the other wild type was gradual. For complete reversal, approximately $5 \times 10^{-3}$ to $1 \times 10^{-1} \mu \mathrm{g}$ arginine $\mathrm{ml}^{-1}$ was required for the wild-type strains, and $1 \mu \mathrm{g}$ arginine $\mathrm{ml}^{-1}$ for the cns mutants. The amount of arginine required for complete reversal of canavanine inhibition therefore appears to be related to the degree of canavanine sensitivity.

The inhibition of $c n s$ strains also decreased with the passage of time. $c n s G$, an allele of an ornithine-requiring mutant $\arg -1$, had a longer lag phase than the wild-type strains in both canavanine $\left(3 \mu \mathrm{g} \mathrm{ml}^{-1}\right)$ medium and minimal medium. On minimal medium, its growth rate was $3.25 \mathrm{~mm} \mathrm{~d}^{-1}$ but on canavanine medium it had an initial rate of $1 \mathrm{~mm} \mathrm{~d}^{-1}$ and then increased to the normal rate after $7 \mathrm{~d}$. The wild-type strain grew at about $3.5 \mathrm{~mm} \mathrm{~d}^{-1}$ from the beginning on both types of medium.

\section{Effects of cns mutations on OCT, OAT and arginase activities}

Ornithine carbamoyltransferase (OCT), arginase and ornithine aminotransferase (OAT) were assayed in some cns and related strains (Table 3). Of the cns mutants examined, only $c n s H$ failed to show detectable OCT activity ( $\leqslant 10 \%$ wild-type OCT). The other mutants 
Table 3. Specific activities of OCT, arginase and OAT in wild-type, pro, pyr, cns and suppressed strains

\begin{tabular}{|c|c|c|c|}
\hline \multirow[b]{2}{*}{ Genotype of strain } & \multicolumn{3}{|c|}{ Specific activities* } \\
\hline & OCT & Arginase & OAT \\
\hline $\begin{array}{l}\text { Wild-type } o_{1} z \\
\text { Wild-type } o_{4} Z\end{array}$ & $\begin{array}{l}3 \cdot 1 \\
5 \cdot 3\end{array}$ & $\begin{array}{l}0.015-0.223 \\
0.021-0.232\end{array}$ & $\begin{array}{l}0.045-0.261 \\
0.115-0.271\end{array}$ \\
\hline $\begin{array}{l}\text { pro- } 1 \dagger \\
\text { pro- } 2 \dagger\end{array}$ & $\begin{array}{l}4 \cdot 2 \\
6 \cdot 3\end{array}$ & $\begin{array}{l}0 \cdot 170 \\
0 \cdot 022-0 \cdot 150 \\
(0 \cdot 129-0 \cdot 329) \ddagger\end{array}$ & $\begin{array}{l}0 \cdot 275 \\
0 \cdot 142 \\
(0 \cdot 275) \ddagger\end{array}$ \\
\hline pyr-3M & $3 \cdot 4$ & - & - \\
\hline $\begin{array}{l}\text { cnsBl } \\
\text { cnsBl pro-1 }\end{array}$ & $\begin{array}{l}3 \cdot 2 \\
3 \cdot 0\end{array}$ & $\begin{array}{l}0.027 \\
0.039\end{array}$ & $\begin{array}{l}0.056-0.230 \\
0.046\end{array}$ \\
\hline $\begin{array}{l}\text { cns DI } \\
\text { cns D1 pro-1 }\end{array}$ & $\begin{array}{l}4 \cdot 3 \\
4 \cdot 1\end{array}$ & $\begin{array}{l}0.006 \\
0.087\end{array}$ & $\begin{array}{l}0.055-0.189 \\
0.150-0.255\end{array}$ \\
\hline $\begin{array}{l}\text { cnsE1 } \\
\text { cnsEI pro-2 }\end{array}$ & $\begin{array}{l}3 \cdot 5 \\
7 \cdot 5\end{array}$ & $\begin{array}{l}0.051 \\
0.025-0.284\end{array}$ & $\begin{array}{l}0.120 \\
0.265\end{array}$ \\
\hline $\begin{array}{l}\text { cnsFI } \\
\text { cnsFI pro-1 }\end{array}$ & $\underline{3 \cdot 8}$ & ${ }^{0.003}$ & $\begin{array}{r}0.025 \\
-\end{array}$ \\
\hline $\begin{array}{l}\text { cnsG1 } \\
\text { cnsG1 pyr-3M }\end{array}$ & $\begin{array}{l}4 \cdot 6 \\
4 \cdot\end{array}$ & 一 & - \\
\hline $\begin{array}{l}\text { cnsHI } \\
\text { cnsH1 pro-l } \\
\text { cnsHl pyr-3M }\end{array}$ & $\begin{array}{l}\text { ND } \\
\text { ND } \\
\text { ND }\end{array}$ & - & - \\
\hline
\end{tabular}

ND, Not detectable; -, not tested.

* Activities are expressed as $\mu$ mol product formed $h^{-1}$ (mg protein $)^{-1}$ based on the average or range for at least two experiments.

$\dagger$ pro- 1 and pro- 2 were cultured in 11 Vogel minimal medium supplemented with $5 \mathrm{mg}$ proline or arginine.

‡ Activities of strains grown in arginine supplemented medium.

showed OCT specific activities which were not significantly lower than in the wild-type strains.

The results of arginase and OAT assays were variable for the strains tested, especially for wild-type and pro- 2 in arginine-free medium. However, the range of activities could be used as a basis for comparison. The specific activities of these enzymes in cnsB1, cnsD1, $c n s E l$ and $c n s F 1$ mutants were slightly lower than or similar to those in wild-type. The pro mutants showed higher activities of arginase and OAT in arginine medium than in proline medium.

\section{Effects of cns on other cns, arg, pro and pyr mutations}

Effects of cns double mutations. Certain cns double mutants showed a requirement for arginine. This is illustrated in a number of crosses between $c n s B$ and $c n s C$, and between $c n s B$ and $c n s E$ (Table 4). In crosses between these $c n s$ mutants (e.g. $c n s B$ and $c n s C$ ), four classes of genotypes [cns $B$, cns $C$ (parental groups), wild-type and $c n s B$ cns $C$ (recombinants)] would be expected with equal frequency assuming no linkage between the two genes involved. If the double mutants $c n s B$ cns $C$ were arginine-requiring, instead of canavanine sensitive like the cns single mutants, a ratio of $2: 1: 1$ for canavanine-sensitive, wild-type and argininerequiring offspring would be obtained. However, this ratio often varied because of different degrees of viability of the mutant spores, particularly those exhibiting the argininerequiring phenotype. To confirm that the arginine-requiring offspring were chs double mutants, the arginine-requiring strains were back-crossed to the wild-type. These crosses produced not only arginine-requiring and wild-type offspring but also canavanine-sensitive offspring, indicating that the arginine-requiring offspring were indeed cns double mutants. In crosses between other cns mutants, no arginine-requiring offspring were found among at 
Table 4. Production of arginine-requiring offspring in crosses of cns mutants

\begin{tabular}{|c|c|c|c|c|}
\hline \multirow[b]{2}{*}{ Cross* } & \multicolumn{4}{|c|}{ No. of offspring } \\
\hline & $\begin{array}{l}\text { Canavanine- } \\
\text { sensitive }\end{array}$ & $\begin{array}{l}\text { Wild- } \\
\text { type }\end{array}$ & $\begin{array}{l}\text { Arginine- } \\
\text { requiring }\end{array}$ & Total \\
\hline $\begin{array}{l}c n s B \times c n s C \\
(11 \text { replicate crosses })\end{array}$ & 1740 & 985 & 325 & 3050 \\
\hline $\begin{array}{l}++\times \text { cnsB } 4 \text { cns } C \\
(2 \text { replicate crosses })\end{array}$ & 395 & 258 & 104 & 757 \\
\hline $\begin{array}{l}c n s B \times c n s E \\
(2 \text { replicate crosses })\end{array}$ & 134 & 77 & 26 & 237 \\
\hline \multirow[t]{2}{*}{$\begin{array}{l}++\times \text { cns } B \text { cnsE } \\
(2 \text { replicate crosses })\end{array}$} & 133 & 82 & 23 & 238 \\
\hline & \multicolumn{3}{|c|}{ Expected ratio $2: 1: 1$} & \\
\hline
\end{tabular}

* Each replicate cross involved cns strains carrying different alleles of the same gene.

least 300 analysed in each cross. Like $\arg -2$ (allele of $c n s C$ ) and $\operatorname{arg-7}$ (allele of cns $B$ ), the arginine-requiring $c n s$ double mutants involving $c n s B, c n s C$ and $c n s E$ grew well on media supplemented with citrulline or arginine at $1 \mu \mathrm{g} \mathrm{ml}^{-1}$. The OCT activity of the double mutants was normal.

Effects of chs on arg mutations. Strains carrying arg-1 and arg-4 responded to ornithine, citrulline or arginine. When $c n s H$ was associated with $\arg -1$ or $\arg -4$, however, the double mutant only responded to citrulline or arginine, suggesting that $c n s H$ prevents the utilization of exogenous ornithine. At a high concentration of ornithine $\left(40 \mathrm{mg} \mathrm{ml}^{-1}\right)$ the double mutants grew poorly, indicating that a very limited amount of exogenously supplied ornithine could be used in these strains. An alternative explanation for the poor growth on this high concentration of ornithine is that the ornithine may be contaminated with traces of arginine or citrulline.

Effects of cns on pro mutations. Certain cns mutants were able to suppress the nutritional requirements of pro mutants when combined with them. Of the cns tested, $c n s B, c n s D, c n s E$, $c n s F$ and $c n s H$ belonged to this group (Table 5). When $c n s$ and pro were crossed, four genotypes [cns, pro, cns pro and wild-type] were expected with equal frequency assuming no linkage between the two genes involved. If there were no suppresion, the double mutant pro cns should have a phenotype similar to the pro single mutant, which was also canavaninesensitive. If suppression occurs, the double mutant should be indistinguishable phenotypically from cns. Thus, if one assumes no linkage or inviability, the ratio of canavaninesensitive to wild-type to proline-requiring offspring would be $1: 1: 2$ without suppression but $2: 1: 1$ with suppression. Because of different degrees of viability in the mutant spores, the segregation of the expected phenotypes did not strictly follow in a $2: 1: 1$ ratio. However, the segregation ratios in most crosses, and the appearance of proline-requiring offspring from back-crosses between presumed double mutants and the wild-type, support the view that certain cns mutations did suppress the nutritional requirements of the pro mutants.

Some of the cns and their pro-suppressed strains grew well in the presence of citrulline or arginine, but grew slowly in the absence of these supplements.

Effects of cns on pyr mutations. Strains carrying $c n s G$ or $c n s H$ in combination with certain pyr-3 alleles (designated $p y r-3 M$ ) were pyrimidine-independent and sensitive to both canavanine and arginine (Table 6). The double mutant cns $G$ pyr-3M was also sensitive to ornithine and, to a greater extent, citrulline and arginine. This inhibitory effect could be overcome by an exogenous supply of uracil. The double mutant cns $H$ pyr-3M was not sensitive to ornithine (Fig. 3).

Double mutants carrying other combinations of $c n s$ with pyr-1, pyr-2 or pyr-3 were all pyrimidine-requiring and canavanine-sensitive, indicating that other cns mutants were not 
Table 5. Suppression of pro mutants by cns mutants

\begin{tabular}{|c|c|c|c|c|}
\hline \multirow[b]{2}{*}{ Cross } & \multicolumn{4}{|c|}{ No. of offspring } \\
\hline & $\begin{array}{l}\text { Canavanine- } \\
\text { sensitive }\end{array}$ & $\begin{array}{l}\text { Wild- } \\
\text { type }\end{array}$ & $\begin{array}{l}\text { Proline- } \\
\text { requiring }\end{array}$ & Total \\
\hline $\begin{array}{l}\text { cns } B 1 \times \text { pro- } 1 \\
\text { cns } B 1 \times \text { pro }-2\end{array}$ & $\begin{array}{l}226 \\
261\end{array}$ & $\begin{array}{l}120 \\
150\end{array}$ & $\begin{array}{r}103 \\
60\end{array}$ & $\begin{array}{l}449 \\
471\end{array}$ \\
\hline $\begin{array}{l}\text { cns } D 1 \times \text { pro- } 1 \\
\text { cns } D 1 \times \text { pro }-2\end{array}$ & $\begin{array}{r}116 \\
47\end{array}$ & $\begin{array}{l}69 \\
35\end{array}$ & $\begin{array}{l}65 \\
22\end{array}$ & $\begin{array}{l}250 \\
104\end{array}$ \\
\hline $\begin{array}{l}c n s E 1 \times \text { pro- } 1 \\
c n s E 1 \times \text { pro- } 2\end{array}$ & $\begin{array}{l}241 \\
175\end{array}$ & $\begin{array}{r}169 \\
97\end{array}$ & $\begin{array}{r}110 \\
30\end{array}$ & $\begin{array}{l}520 \\
302\end{array}$ \\
\hline $\begin{array}{l}c n s F 1 \times \text { pro- } 1 \\
c n s F 1 \times \text { pro- } 2\end{array}$ & $\begin{array}{l}150 \\
172\end{array}$ & $\begin{array}{l}81 \\
87\end{array}$ & $\begin{array}{l}60 \\
43\end{array}$ & $\begin{array}{l}291 \\
302\end{array}$ \\
\hline $\begin{array}{l}\text { cnsH1 } 1 \times \text { pro- }-1 \\
\text { cnsH } 1 \times \text { pro }-2\end{array}$ & $\begin{array}{r}122 \\
83\end{array}$ & $\begin{array}{l}74 \\
46\end{array}$ & $\begin{array}{l}54 \\
31\end{array}$ & $\begin{array}{l}250 \\
160\end{array}$ \\
\hline $\begin{array}{l}++\times \text { cnsBl pro-1 } \\
++\times \text { cnsD1 pro- } 1 \\
++\times \text { cnsE1 pro }-2 \\
++\times \text { cnsF1 pro }-1 \\
++\times \text { cnsHI pro- } 2\end{array}$ & $\begin{array}{r}208 \\
149 \\
101 \\
113 \\
86\end{array}$ & $\begin{array}{r}106 \\
96 \\
48 \\
89 \\
54\end{array}$ & $\begin{array}{l}95 \\
85 \\
25 \\
47 \\
33\end{array}$ & $\begin{array}{l}409 \\
330 \\
174 \\
249 \\
173\end{array}$ \\
\hline
\end{tabular}

Table 6. Suppression of pyr-3M by cns mutants

\begin{tabular}{|c|c|c|c|c|c|}
\hline \multirow[b]{2}{*}{ Cross* } & \multicolumn{5}{|c|}{ No. of offspring } \\
\hline & cns & pyr & ++ & cns pyr $\dagger$ & Total \\
\hline $\begin{array}{l}c n s G \times p y r-3 M \\
\text { (2) } 2 \text { replicate crosses) }\end{array}$ & 116 & 106 & 239 & 131 & 592 \\
\hline $\begin{array}{c}++\times c n s G \text { pyr- } 3 M \dagger \\
(3 \text { replicate crosses })\end{array}$ & 94 & 83 & 91 & 79 & 347 \\
\hline $\begin{array}{l}\text { cns } H \times p y r-3 M \\
(2 \text { replicate crosses })\end{array}$ & 44 & 26 & 67 & 23 & 160 \\
\hline $\begin{array}{c}++\times \text { cnsH pyr- } 3 M \dagger \\
\text { (2 replicate crosses) }\end{array}$ & 48 & 25 & 66 & 21 & 160 \\
\hline
\end{tabular}

* Each replicate cross involved cns strains carrying different alleles of the same gene. $\dagger$ Pyrimidine-independent and sensitive to canavanine or arginine.

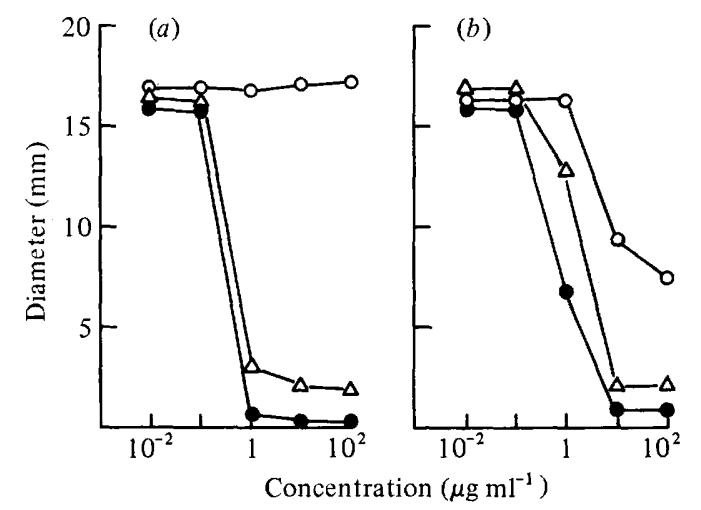

Fig. 3. Effect of different concentrations of ornithine $(O)$, citrulline $(\triangle)$ and arginine $(\Theta)$ on the growth of $(a) c n s H 1$ pyr-3M and $(b) c n s G 1$ pyr-3M mutants. Growth was expressed as the mean diameter of four colonies measured $6 \mathrm{~d}$ after inoculation. 
Table 7. Free arginine contents of mycelia of wild-type and chs strains with different degrees of canavanine inhibition

\begin{tabular}{|c|c|c|c|}
\hline \multirow[b]{2}{*}{ Genotype of strain } & \multicolumn{2}{|c|}{$\begin{array}{c}\text { Free arginine } \\
{\left[\mathrm{mg}(\mathrm{g} \text { dry mycelium })^{-1}\right]}\end{array}$} & \multirow{2}{*}{$\begin{array}{c}\text { Inhibition } \\
\text { by } 2 \mu \mathrm{g} \\
\text { canavanine } \mathrm{ml}^{-1} \\
(\%)\end{array}$} \\
\hline & $3 \mathrm{~d}$-old & $4 \mathrm{~d}$-old & \\
\hline $\begin{array}{l}\text { Wild-type } o_{1} \mathrm{Z} \\
\text { Wild-type } \mathrm{o}_{4} \mathrm{Z} \\
\text { cnsB3 } \\
\text { cnsC1 } \\
\text { cnsD1 } \\
\text { cnsE1 } \\
\text { cnsG1 } \\
\text { cnsH1 }\end{array}$ & $\begin{array}{l}8 \cdot 6 \\
6 \cdot 0 \\
3 \cdot 4 \\
2 \cdot 2 \\
3 \cdot 9 \\
\frac{-}{2 \cdot 5}\end{array}$ & $\begin{array}{l}5 \cdot 5 \\
5 \cdot 3 \\
2 \cdot 3 \\
1 \cdot 0 \\
3 \cdot 9 \\
2 \cdot 8 \\
2 \cdot 6 \\
2 \cdot 2\end{array}$ & $\begin{array}{r}2 \cdot 9 \\
8 \cdot 8 \\
95 \cdot 5 \\
93 \cdot 5 \\
94 \cdot 0 \\
80 \cdot 0 \\
88 \cdot 0 \\
100 \cdot 0\end{array}$ \\
\hline & -, Not & & \\
\hline
\end{tabular}

able to nullify the effect of the pyr mutations. Furthermore, $c n s G$ and $c n s H$ were unable to act as suppressors for some $p y r-3$ alleles, designated as $p y r-3 M N$ or $p y r-3 N$. This locus is thought to code for a bifunctional enzyme.

\section{Effect of cns mutations on content of free arginine}

The free arginine contents of 3 and 4 d-old mycelia of two wild-type $\left(\mathrm{o}_{1} \mathrm{z}\right.$ and $\left.\mathrm{o}_{4} \mathrm{z}\right)$ and six cns strains grown in arginine-free medium are summarized in Table 7 . The wild-type strains were only inhibited by 2.9 to $8.8 \%$ in medium supplemented with $2 \mu \mathrm{g}$ canavanine $\mathrm{ml}^{-1}$, whereas the mutants were at least $80 \%$ inhibited. The free arginine content in the wild-type strains [5.3 to $8.6 \mathrm{mg}$ (g dry mycelium) ${ }^{-1}$ ] was much higher than in the cns strains tested. Mycelia from cnsB3, cnsC1, cnsD1, cnsE1, cns 1 1 and $c n s H 1$ strains contained $39 \cdot 5$ to $56 \cdot 7 \%$, 18.2 to $36.7 \%, 45 \cdot 4$ to $73.6 \%, 50.9$ to $52.8 \%, 47 \cdot 3$ to $49.1 \%$ and $29 \cdot 1$ to $41.5 \%$, respectively, of the wild-type amount of arginine.

Attempts to detect arginine by the Sakaguchi reaction in media in which Coniochaeta strains had grown were unsuccessful. A more sensitive bioassay method was therefore used to estimate arginine. The arginine tester strain, arg-3, grew slowly on the culture medium of the wild-type strain and the amount of arginine excreted into the medium was calculated to be about $6 \mu \mathrm{g}$ (g dry mycelium) ${ }^{-1}$. No growth occurred in medium in which chs mutants had been grown showing that no arginine could be detected by this method.

\section{DISCUSSION}

Nature of canavanine sensitivity. In Coniochaeta, canavanine sensitivity has been shown to result from the impairment of arginine synthesis. Of the eight distinct groups of cns mutants, five were presumably blocked in steps leading to arginine biosynthesis (see Fig. 4 and Table 8). The others were also shown to be affected in arginine metabolism. All the cns mutants tested had less free arginine in their mycelia and in their culture media than the wild-type strains. In addition, certain groups of cns double mutants ( $c n s B$ cns $C$ and $c n s B$ cnsE) were citrulline-requiring, whereas the original cns single mutants were citrulline-independent. Certain slow-growing cns and pro-suppressed strains required arginine for good growth. These findings are consistent with the hypothesis that the level of intracellular arginine determines the sensitivity or resistance to canavanine in Coniochaeta.

Although the cause of a difference in intracellular arginine levels may vary, canavanine sensitivity of some micro-organisms can be explained by the above hypothesis. Weglenski (1967) has reported that wild-type Aspergillus, which possessed more intracellular arginine 
Table 8. Summary of genetic locations, proposed enzymic lesions, suppression or interaction effects of cns loci

\begin{tabular}{|c|c|c|c|c|}
\hline Locus & $\begin{array}{l}\text { Presumed } \\
\text { to be } \\
\text { allelic } \\
\text { with }\end{array}$ & $\begin{array}{l}\text { Suppression } \\
\text { of }\end{array}$ & $\begin{array}{l}\text { Proposed enzymic } \\
\text { lesions }\end{array}$ & Comments \\
\hline cns $A$ & arg-3 & - & $\begin{array}{l}\text { Arginine-synthesizing } \\
\text { enzyme(s) }\end{array}$ & $\arg -3$ is an arginine requirer \\
\hline$c n s B$ & arg-7 & pro-1, 2 & $\begin{array}{l}\text { Carbamoyl phosphate } \\
\text { synthase - arginine } \\
\text { synthesis }\end{array}$ & $\begin{array}{l}\arg -7 \text { is a citrulline requirer; } c n s B \text { cns } C \\
\text { and } c n s B \text { cnsE require citrulline }\end{array}$ \\
\hline cnsC & $\arg -2$ & - & $\begin{array}{l}\text { Carbamoyl phosphate } \\
\text { synthase - arginine } \\
\text { synthesis }\end{array}$ & $\begin{array}{l}\text { arg-2 is a citrulline requirer; mapped on } \\
\text { linkage group II; cns } B \text { cns } C \text { requires } \\
\text { citrulline }\end{array}$ \\
\hline cns D & - & pro- 1,2 & - & - \\
\hline cnsE & - & pro-1,2 & - & $c n s B$ cnsE requires citrulline \\
\hline cnsF & - & pro-1, 2 & - & Mapped on linkage group III \\
\hline cnsG & $\arg -1$ & $p y r-3 M$ & $\begin{array}{l}\text { Ornithine-synthesizing } \\
\text { enzyme(s) }\end{array}$ & $\begin{array}{l}\text { arg-1 is an ornithine requirer; } \\
\text { cns } \text { pyr- } 3 M \text { is sensitive to ornithine, } \\
\text { citrulline and arginine; these sensitivities } \\
\text { could be overcome by uracil }\end{array}$ \\
\hline$c n s H$ & 一 & $\begin{array}{l}\text { pro- }-1,2 \text { and } \\
\text { pyr-3M }\end{array}$ & $\begin{array}{l}\text { Ornithine carbamoyl- } \\
\text { transferase }\end{array}$ & $\begin{array}{l}\text { cns } H \text { pyr- } 3 M \text { is sensitive to citrulline and } \\
\text { arginine; these sensitivities could be } \\
\text { overcome by uracil; } c n s H \text { arg- } 1 \text { and } \\
\text { cns } H \text { arg- } 4 \text { could not respond to } \\
\text { ornithine, in contrast to arg- } 1 \text { and } \\
\text { arg-4 }\end{array}$ \\
\hline
\end{tabular}

than a pro suppressor strain, was less sensitive to canavanine. Schwartz \& Maas (1960) reported that canavanine inhibited the growth of $E$. coli almost completely in the presence of low intracellular arginine while normal growth was observed in the presence of high intracellular arginine. Strains of E. coli (Maas, 1961) and Saccharomyces (Bechet et al., 1970) which produce excess arginine through a loss of regulation of arginine synthesis are more resistant to canavanine than the wild-type. The hypothesis, however, has not been used to explain canavanine sensitivity or resistance in Neurospora (Bauerle, 1963; Logan, 1969).

In view of the evidence presented for cns mutations in Coniochaeta, we can rule out the following mechanisms as possible explanations for the genetic defects: (i) an alteration of uptake system(s); (ii) an alteration of RNA synthetase or related protein-synthesizing machinery; (iii) a loss of control of arginine biosynthesis in response to canavanine or arginine; and (iv) a canavanine-detoxifying system. However, some of these mechanisms may explain other cns mutants which have not yet been isolated in this fungus.

Pyrimidine, arginine and proline pathways. The effects of chs mutations on the pyrimidine and proline mutants revealed similarities in the pyrimidine, arginine and proline pathways between Coniochaeta and Neurospora. In the pyrimidine pathway, a complex locus, pyr-3, presumably specifying the bifunctional protein carbamoyl-phosphate synthase (CPS-P) and aspartate carbamoyltransferase (ACT), was detected. $c n s H$ was able to distinguish the suppressible $p y r-3 M$ (presumably CPS-P defective), the non-suppressible $p y r-3 N$ (presumably ACT defective) and pyr-3MN (presumably defective in CPS-P and ACT). These pyr mutants, however, mapped at a single locus known as pyr-3. A similar locus has also been described in Neurospora (Suyama et al., 1959; Davis \& Woodward, 1962; Woodward $\&$ Davis, 1963). In the arginine pathway, cns mutants such as $c n s B, c n s C$ and $c n s H$ have helped to clarify the metabolic positions of $\arg -2$ and $\arg -7$. These two $\arg$ mutations cause blocks prior to citrulline synthesis in the pathway. It has now been confirmed that they appear to be loci specifying carbamoyl-phosphate synthase (CPS-A) in the arginine pathway because both these citrulline-requiring mutants are distinct from $c n s H$ (OCT defective strain) 


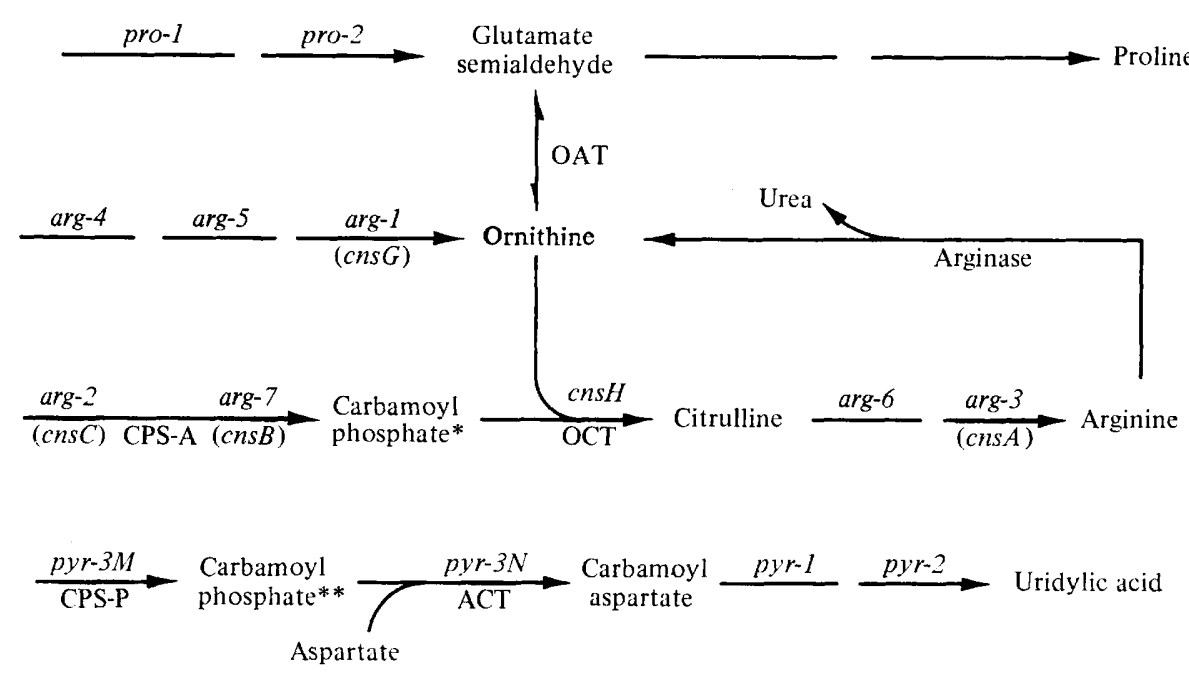

Fig. 4. Proposed metabolic relationships between the pyrimidine, arginine and proline pathways of Coniochaeta. Genes shown in parentheses are allelic or very tightly linked to those shown directly above them. Enzymes: CPS-A, carbamoyl-phosphate synthase - arginine synthesis; CPS-P, carbamoyl-phosphate synthase - pyrimidine synthesis; ACT, aspartate carbamoyltransferase; OAT, ornithine aminotransferase; OCT, ornithine carbamoyltransferase. * and ** indicate carbamoyl phosphate for arginine synthesis and pyrimidine synthesis, respectively.

in their genetic locations and OCT activity. Like Neurospora (Davis, 1967, 1972) the two arg loci were considered to produce two polypeptide subunits which in turn constituted CPS-A. This is also supported by the fact that cnsB and cnsC (alleles of arg-7 and arg-2, respectively) when combined as the double mutants are phenotypically citrulline-requiring and exhibit normal OCT activity. If the products of $c n s B$ and $c n s C$ represent partially defective polypeptides coded by arg-7 and $\arg -2$, respectively, it is conceivable that a nonfunctional distorted enzyme would be produced in the double mutants $c n s B c n s C$.

pro strains exhibited higher activity of arginase and OAT in the presence of arginine than in the proline media. This probably reflects the fact that both arginase and OAT are inducible enzymes as they are in Neurospora (Davis et al., 1970) and Aspergillus (Weglenski, 1967).

The auxotrophic behaviour of pyr-3M, arg- 2 and $\arg -7$ suggests that there are two separate carbamoyl phosphate (CAP) pools, one specific for the pyrimidine pathway (CAPpyr) and one specific for the arginine pathway (CAParg). The two CAP pools are not easily accessible to the alternative pathways unless mutations which bring about 'dechannelling' occur. This phenomenon has been observed in Neurospora (Davis, 1967; Reissig et al., 1967) but it differs from that of Saccharomyces in which the CAParg and CAPpyr, although governed by different enzymes, are accessible to both pathways (Lacroute et al., 1965).

The effect of $c n s H$ on the phenotype of ornithine requirers parallels a similar situation observed by Davis (1968) in Neurospora. He postulated that there was a competitive effect of OCT and OAT for a common substrate ornithine and differential utilization of endogenous and exogenous ornithine. In wild-type Neurospora, OCT has higher affinity for endogenous ornithine than OAT; thus the endogenous ornithine is used mainly for the OCT reaction and is practically unavailable for the OAT reaction. In contrast, exogenous ornithine is used mainly for OAT reactions. A similar situation may exist in Coniochaeta.

From the above findings and some earlier observations (Tan, 1968; Paterson et al., 1969) a proposed metabolic relationship between the pyrimidine, arginine and proline pathways, with relevant genes and enzymes, has been formulated for Coniochaeta (Fig. 4).

Mode of pyr and pro suppression. In Coniochaeta, $c n s G$ and $c n s H$ are two distinct groups 
of pyr-3M suppressors. $c n s G$ was affected in ornithine synthesis while $c n s H$ was affected in OCT reaction. The former could suppress $p y r-3 M$ mutants while the latter could suppress both the pyr-3M and pro-1 or pro-2 mutants. Suppressors with the above metabolic defects have been described in Neurospora (Mitchell \& Mitchell, 1952; Davis, 1962; Wieland \& McDougall, 1969) and Coprinus (Cabet et al., 1965). The cns $G$ mutation is believed to result in a reduction of ornithine which limits citrulline formation. This would lead to an accumulation of CAParg, which, in excess, could be used by ACT for pyrimidine synthesis. Addition of ornithine, citrulline or arginine would be expected to prevent this accumulation thus causing the observed reduction in growth. The $c n s H$ mutation would cause an accumulation of CAParg and ornithine due to a reduction of OCT reaction. This excess CAParg could be used in the pyrimidine pathway while ornithine could be used for proline synthesis. Addition of arginine or citrulline would reduce ornithine synthesis but the addition of ornithine would not cause inhibition as observed.

$c n s B, c n s D, c n s E$ and $c n s F$ are new pro suppressors of Coniochaeta which, to our knowledge, have not been reported in other filamentous fungi. cns $B$, presumably being affected in CPS-A, would produce less CAParg which would limit the OCT reaction. As a result, endogenous ornithine would accumulate and become available for proline synthesis via OAT. On the other hand, $c n s D, c n s E$ and $c n s F$ may be regarded as mutations affecting the regulation of certain enzymes or the property of enzyme compartment in the arginine pathway. These types of mutations would also allow the endogenous ornithine to be channelled to the proline pathway. Further study on these cns mutants may provide new information on the regulation of arginine biosynthesis in Coniochaeta and possibly filamentous fungi as a whole.

This paper forms part of the Ph.D. thesis submitted to the Queen's University of Canada by $\mathrm{H}$. Tan who was a recipient of an Ontario Graduate Fellowship. We are grateful to Dr D. H. Bone for his constant interest and suggestion in the course of the work, and to Professors R. H. Davis, D. Perkins and C. C. Ho for their helpful comments on the manuscript. This work was also supported by grants from the Department of Fisheries and Forestry, National Research Council, and the Department of University Affairs of Canada.

\section{REFERENCES}

Albrecht, A. M., Scher, W. I. \& Vogel, H. J. (1962). Determination of aliphatic aldehydes by spectrophotometry. Analytical Chemistry 34, 398-400.

BAUERLE, R. (1963). The metabolism of canavanine in a threonine-less mutant of Neurospora crassa. Ph.D. thesis, Purdue University, Indiana, U.S.A.

BAuERle, R. H. \& Garner, H. R. (1964). The assimilation of arginine and lysine in canavanine resistant and sensitive strains of Neurospora crassa. Biochimica et biophysica acta 93, 316-322.

Bechet, J., Grenson, M. \& WiaMe, J. M. (1970). Mutants affecting the repressibility of arginine biosynthetic enzymes in Saccharomyces cerevisiae. European Journal of Biochemistry 12, 31-39.

Cabet, D., Gans, M., Hirsch, M. L. \& Prevost, G. (1965). Mode d'action de deux gènes suppresseurs de l'effect des gènes ur-1-a chez Coprinus radiatus. Comptes rendus hebdomadaire des séances de l'Académie des sciences 261, 5191-5194.

CoOKe, F., TAN, H. \& Good, H. M. (1969). An introduction to the genetics of the fungus Coniochaeta velutina. Canadian Journal of Botany 47, 1019-1026.
Davis, R. H. (1962). Consequences of a suppressor gene effective with pyrimidine and proline mutants of Neurospora. Genetics 47, 351-360.

Davis, R. H. (1967). Channelling in Neurospora metabolism. In Organizational Biosynthesis, pp. 303-322. Edited by H. J. Vogel, J. O. Lampen \& V. Bryson. New York: Academic Press.

DAvis, R. H. (1968). Utilization of exogenous and endogenous ornithine by Neurospora crassa. Journal of Bacteriology 96, 389-395.

DAVIS, R. H. (1972). Metabolite distribution in cells. Science 178, 835-840.

Davis, R. H. \& Woodward, V. W. (1962). The relationship between gene suppression and aspartate transcarbamylase activity in pyr-3 mutants of Neurospora. Genetics 47, 1075-1083.

Davis, R. H., Lawless, M. B. \& Port, L. A. (1970). Arginaseless Neurospora: genetics, physiology and polyamine synthesis. Journal of Bacteriology 102, 299-305.

Doermamn, A. A. (1954). A bioassay for lysine by use of a mutant of Neurospora. Journal of Bacteriology 49, 315.

Kalyankar, G. D., Ikawa, M. \& Snell, E. E. 
(1958). The enzymatic cleavage of canavanine to homoserine and hydroxy-guanidine. Journal of Biological Chemistry 233, 1175-1177.

KiharA, H. \& Snell, E. E. (1957). The enzymatic cleavage of canavanine to $o$-ureidohomoserine and ammonia. Journal of Biological Chemistry 226, 485-495.

KnivetT, V. A. (1954). The effect of arsenate on bacterial citrulline breakdown. Biochemical Journal 56, 606-610.

Lacroute, F., Pierard, A., Grenson, M. \& WIAME, J. M. (1965). The biosynthesis of carbamyl phosphate in Saccharomyces cerevisiae. Journal of General Microbiology 40, 127-142.

LoGAN, J. B. (1969). Biochemistry and genetics of canavanine resistance in Neurospora. Ph.D. thesis, California Institute of Technology, Pasadena, U.S.A.

Lowry, O. H., Rosebrough, N. J., Farr, A. L. \& Randall, R. J. (1951). Protein measurement with the Folin phenol reagent. Journal of Biological Chemistry 193, 265-275.

MAAS, W. K. (1961). Studies on repression of arginine biosynthesis in Escherichia coli. Cold Spring Harbor Symposia on Quantitative Biology 26, 183-191.

MARKERT, C. L. (1952). Radiation-induced nutritional and morphological mutants of Glomerella. Genetics 37, 339-352.

Mrtchell, M. B. \& Mitchell, H. K. (1952). Observation on the behaviour of suppression in Neurospora. Proceedings of the National Academy of Sciences of the United States of America 38, 205-214.

MOYED, H. S. (1964). Biochemical mechanisms of drug resistance. Annual Review of Microbiology 18, 347-366.

PAterson, M. C. (1969). Mutation studies on Coniochaeta velutina. M.Sc. thesis, Queen's University, Ontario, Canada.

Paterson, M. C., TAN, H. \& CoOke, F. (1969). Mutation spectrum in the fungus Coniochaeta velutina. Canadian Journal of Genetics and Cytology 11, 870-879.
Reissig, J. L., Issaly, A. S. \& DE IsSaly, J. M. (1967). Arginine-pyrimidine pathways in microorganisms. National Cancer Institute Monograph 27, 259-271.

RichMOND, M. H. (1965). The enzymatic basis of specific antibacterial action by structural analogues. Biological Reviews 40, 93-128.

Schwartz, J. H. \& MAas, W. K. (1960). Analysis of the inhibition of growth produced by canavanine in Escherichia coli. Journal of Bacteriology 79, 794-799.

SuYama, Y., Munkres, K. D. \& Woodward, V. W. (1959). Genetic analysis of the pyr-3 locus of Neurospora crassa: the bearing of recombination and gene conversion upon interallelic linearity. Genetica 30, 293-311.

TAN, H. (1968). An introduction to the genetics of the fungus Coniochaeta velutina. M.Sc. thesis, Queen's University, Ontario, Canada.

TAN, H. (1971). Canavanine sensitive mutants in Coniochaeta velutina. Ph.D. thesis, Queen's University, Ontario, Canada.

TAN, H. \& Cooke, F. (1969). Arginine mutants and canavanine sensitivity in Coniochaeta velutina. Canadian Journal of Genetics and Cytology 11, 483 (abstract).

Van Pilsum, J. E., Berman, D. A. \& Wolin, E. A. (1957). Assay and some properties of kidney transaminase. Proceedings of the Society for Experimental Biology and Medicine 95, 96-100.

VoGEL, H. J. (1956). A convenient growth medium for Neurospora. Microbial Genetics Bulletin 13, 42-43.

WEGLENSKI, P. (1967). The mechanism of action of proline suppressors in Aspergillus nidulans. Journal of General Microbiology 47, 77-85.

Wieland, C. R. \& MCDougall, K. J. (1969). Suppression of pyr-3 mutants by am mutants in Neurospora. Genetics 61 (2), suppl. S62-S63.

WoodwaRd, V. W. \& Davis, R. H. (1963). Coordinate changes in complementation, suppression and enzyme phenotypes of a pyr-3 mutant of Neurospora crassa. Heredity 18, 21-25. 